\title{
Visualising the Development of a Teacher-In-Training into a Beginning Expert
}

\author{
Walter M. Geerts ${ }^{1}$, Henderien W. Steenbeek ${ }^{2} \&$ Paul L. C. van Geert ${ }^{2}$ \\ ${ }^{1}$ Department of Teacher Education, NHL University of Applied Sciences, Leeuwarden, The Netherlands \\ ${ }^{2}$ Department of Developmental Psychology, University of Groningen, Groningen, The Netherlands \\ Correspondence: Walter M. Geerts, Department of Teacher Education, NHL University of Applied Sciences, \\ Leeuwarden, The Netherlands. Tolhuisweg 24a, 9475 PG, Midlaren, The Netherlands. Tel: 31-6-3629-0124. \\ E-mail: w.m.geerts@nhl.nl
}

Received: July 14, 2017

doi:10.5539/ies.v10n12p1
Accepted: August 20, 2017 Online Published: November 28, 2017

URL: https://doi.org/10.5539/ies.v10n12p1

\begin{abstract}
Teachers use situated knowledge to deal with the complex and diffuse educational contexts they operate in. To be able to take deliberated action, based on the situated knowledge, reflection is necessary during the teacher training. Video cases with common, real world situations are suitable for reflection because of their holistic and diffuse character. Reflection concerns learning experiences with increasing complexity: single-loop (reflecting on a current action), double-loop (reflecting to gain new insights) and triple-loop (reflecting in order to adjust individual identity) learning. The knowledge gained from loop learning is of a situated nature. The current article operationalizes situated knowledge as educational purposes and design patterns; educational purposes determine which course of action (design pattern), is the best option. Using this distinction, we investigate whether the reflection done by fourth-year teachers in training corresponds to what can be expected of a starting expert, namely, reflection on all three levels. The results indicate that three out of four teachers in training can be characterized as starting experts, based on their responses to a video case. They experience learning on all three loop levels, and these experiences contribute to a variety of educational purposes and design patterns. It is the teacher trainers' challenge to have their students reflects using video cases, so they can use loop-learning to build their situated knowledge. This knowledge will allow them to adequately respond to the complex and diffuse situations in their educational practice.
\end{abstract}

Keywords: loop learning, pre-service teacher, reflection, situated knowledge, teacher training, video case

\section{Introduction}

Hattie has stated that a key component of high quality education is the teacher who is teaching the lessons (2003). Students are expected to reach educational goals, among other in the form of specific cognitive levels, but for them to do so requires high quality teachers to be giving the lessons that can take them to that level (Dean, Lauer, \& Urquhart, 2005). The process that makes one a high-quality teacher starts at the teacher training. At the end of the teacher training, the teacher in training should attain the level of beginning expert as a basic qualification.

Van der Grift defines a starting expert teacher as "being able to adequately handle the most common situations in a classroom, which are mostly of a diffuse nature" (2010). He further specifies this description by stating that a starting expert should be able to create a safe learning environment, employ an efficient organization of his lessons and use clear instructions. In this article, a purely pragmatic definition of a starting expert is used, namely a final year student of the teacher training. Starting experts can become full experts, who are generally experienced and act intuitively and effectively in the dynamic environment that is their daily educational workspace (Markauskaite \& Goodyear, 2014). Acting intuitively means to know, either consciously or automatically, which goals are to be reached and how this can be done. Whereas effective means that their actions contribute to the goal they set. The setting or situation of the intuitive, effective action is inseparably linked to the necessary knowledge that is acquired, created or used to deal with that situation. In short, the necessary knowledge is of a situated nature. This research focuses on the question to what extent the situated knowledge of a teacher in the fourth year of his training corresponds to the situated knowledge of a starting expert. 


\subsection{Situated Knowledge}

Situated knowledge is contextual and holistic and arises from the interaction between previous experiences and the theoretical knowledge linked to those experiences. Its components are inseparably linked to the interaction and situation it was created in. In this article, therefore, situated knowledge is defined as cognition that arises from and is connected to the interactions the material body of an agent entertains with its physical environment (Roth \& Jornet, 2013). Physical environments, or workplace situations, often demand immediate, quick or intuitive actions by the teacher. For example, when a teacher at work observes that the physical distance he puts between himself and his students affects their behaviour, he will conclude that he can make his students aware of his focus by standing closer to them (Miller, 2011). A teacher in training has not yet internalized this situated knowledge that will allow him to act quickly and intuitively in situations like these. To be able to deal with the constantly changing educational practice, teachers in training need to learn how to link the theory they studied in their training with what goes on in their workplace (Geerts, Van der Werff, Hummel, Steenbeek, \& Van Geert, 2015; Ching, 2014). Situated actions are created from this link. They are built on previous teaching experiences, linking those situations with appropriate theoretical concepts and the underlying principles that originated in this process.

The underlying principles that a teacher created this way are, for example the realization that it is the teacher's job to take corrective action when necessary, to be responsible for the continuity of the lesson (or momentum, in teaching terminology, to keep the lesson constantly moving forward) and to be a group leader. Copeland and D'Emidio-Caston (1998) call these principles that underpin a teacher's actions, educational purposes: the constantly changing process goals a teacher sets for himself to conduct the lesson in the way that seems best to him. The educational purposes guide the choices he makes regarding his actions. Indeed, the goal determines the actions and decisions that might benefit reaching that goal. Every educational purpose, for example, watching over the lesson's momentum, guides what the teacher does in his workplace.

Once a teacher in training knows what he wants to achieve with his actions, he still needs to solve problems during the execution of his plans and actions. Many of these problems will be recurring. These recurring problems require actions which are called design patterns. A design pattern is a pattern of solutions for a recurring problem that a teacher can use in his teaching practice. A design pattern can only be called as such if it is transferable. However, before it can be transferred, it needs to be very clear what the design pattern is about. This can become apparent by writing out the necessary knowledge and heuristics on paper (Alexander et al., 1977). An experienced teacher trainer might be able to completely describe a design pattern on paper. This does not mean, however, that it is easily transferred from one teacher to another. Since the knowledge contained in the design pattern is situated, the pattern can only be learned by interacting with a real-world teaching situation. Furthermore, an experienced teacher will apply a design pattern more or less unconsciously, because of the intuitive nature of the knowledge contained in it. In this case, the knowledge that was at first explicit, controlled and discursive to the teacher, has become automatic. Summarizing, it can be said that an experienced teacher is an expert in his field, who can act intuitively and effectively by using his situated knowledge, which consists of educational purposes and design patterns.

\subsection{Reflecting on Video Cases}

Collecting this type of situated knowledge is encouraged in the teacher training's curriculum, both by offering real-world experience as well as theoretical knowledge. Practical experiences, mostly internships, are momentary by nature, however. Showing video cases at their regular classes on the educational theories allows teachers in training to reflect on the practical experience they gained during their internship. Because this allows the teacher in training to use reflection to integrate his theoretical knowledge and his practical experiences, using video cases is a useful didacticism for future teachers to acquire situated knowledge.

Reflection can contribute to the way a beginner develops into an expert. Fischer (1980) developed a framework to understand this process. His skill theory posits that beginners make connections between what they recently learned and what they already knew. They connect the old knowledge with the new, or give new meaning to the old knowledge. According to Fischer, skills are a dynamic process. The features of dynamic skills are deeply rooted in the actual content (Van Geert \& Fischer, 2009), which very closely resembles the definition of situated knowledge. The skill theory also implies that cognitive frameworks are used to solve problems and that solving the problems leads to new learning by, for example, placing different elements of the skill 'classroom management' into the appropriate framework. The fact that momentum in a lesson can also have a positive effect on classroom management has a place in that framework.

According to Fischer's skill theory, once the earliest stages of development have been completed, the ways in 
which individuals develop can be split into two levels: representative and abstract. An individual who mentally manipulates concrete representations of people, events and objects, is operating on the representational level. Once this person starts doing the same with abstractions like values or assumptions, the focus shifts to the second level: development on the abstract level (Kitchener \& King, 2004). At the teacher training facilities in the Netherlands, Fischer's theory and the accompanying term 'reflection' are not that often used. Instead, Argyris' loop learning theory is prevalent. As the basic notions underlying loop earning are explicated in skill theory, it offers a useful theoretical underpinning of the concepts used in loop learning theory.

\subsection{Loop Learning}

Like Fischer's skill theory, loop learning is about cognitive development (Argyris, 2002). When beginners, while progressing towards expertness, encounter situations in which they do not know how to react adequately, cognitive development occurs (Ericsson, 2008). Using the responses they got in that situation, combined with the help they received from other experts, they will actively try to fix the problem in similar situations. Once it has been tried out, the effectiveness of the new solution is appraised by reflecting on their behaviour in the situation. In case it was not effective, new possibilities will be tried out, and this cyclical movement is the reason for the name loop learning. To Argyris, learning involves discovering and correcting mistakes, so learning also includes reflecting. The central part reflection plays is entirely consistent with Piaget's theory. Reflection, according to Piaget, serves to cognitively view action characteristics as separate from their form. This allows them to be combined with characteristics of different actions (Piaget, 1972; Dubinsky, 1991; Abrahamson \& Sánchez-García, 2016).

These new combinations are constructed at a higher mental abstraction level, and in this way new knowledge is created. For both Argyris as Piaget and clearly also for Fischer, reflection is a fundamental developmental mechanism and is therefore seen as the driving force behind learning experiences.

The result of the learning process, according to Argyris (2002), occurs on three different reflection levels, i.e. single-loop with 'what do I do', double-loop with 'what new insights have I gained' and triple-loop with 'what kind of teacher do I want to be'. Single-loop learning deals with improving existing action patterns that a teacher in training uses to reach the underlying goal. Double-loop learning occurs when the teacher in training becomes aware of new insights that underpin his teaching. Such new insights can change the way he behaves as a teacher. Triple-loop learning, finally, means that the teacher in training uses reflection to get a better view of the principles he has. Those principles stem from the identity of the teacher and indicate what the teacher thinks is important. Identity, in turn, reflects the character or the person's self. From this self, he will question the higher goal that he strives for. This not only depends on his current identity, but also on the outcome of this reflection that further determines his development.

These three levels can be related to the way Fischer's skill theory describes cognitive development. The way activities and actions are reflected on and subsequently adjusted, is described in skill theory in the first level (actions tier), while Argyris refers to this as single-loop learning. Both theories place the process in which objects, people and events are the subject of reflective thinking, in the first level.

Double loop learning, however, not only deals with adjusting actions but with reconsidering, for example, norms, goals or policies. This can to a certain extent be compared to Fischer's first level, because it concerns reflecting on mental representations of objects, people and events (Kitchener \& King, 2004). However, it also deals with a higher level, because it concerns a reconsideration that can only come about when the person in question realizes that his concrete actions are part of abstract concepts.

In both models, the top level is reserved for thinking at a meta-cognitive level. Triple-loop learning occurs when learning about learning occurs, for example following an earlier loop by reflecting on the learning process itself and what the role of the reflecting person was. At the highest level of his skill theory, as with Argyris' triple-loop learning, Fischer talks about integrating or manipulating abstract concepts, for example by reflecting on them (Kitchener \& King, 2004). The way both models work is illustrated here using the example below of a teacher in training who is unable to capture his students' attention during the lesson.

A teacher in training who is on his way to become a teacher uses, just like anyone who undergoes a cognitive development, feedback loops. Whenever something does not work for this person, something else will be tried, evaluated and the information gained from the process is saved for the future. The three loops in Argyris model represent three distinct levels of complexity in this process.

Loop learning on the first level concerns, for example, perfecting the art of attracting the attention of a distracted student. When the teacher in training notices that the student responds better when his name is used instead of 
general instructions, he will try to use a student's name when calling them to order. When the student immediately responds and pays attention, the action has proven to be effective, and the loop is completed. However, when the action proves to be ineffective he can, for example, choose to take punitive action, which he may have learned at the teacher training, and which starts a new loop.

Double-loop learning, for example, describes a teacher in training who realizes that smooth, uninterrupted transitions between lesson components are more important than correcting students. Gaining this insight concerns double-loop learning, as this insight into his norms only came to be after the unsuccessful attempts to mechanically perfect the art of attracting the attention of a distracted student, as described in the first loop.

The third loop can be elucidated using an elaboration of the previously mentioned example of a teacher who is unable to capture the students' attention, no matter the way he manipulates his actions or applies new insights. Finally, he realizes that he needs to take his responsibility and fulfill the role of group leader, which is unnatural to him. His reflection has led him beyond changing his actions or norms, but instead to developing a new identity, and therefore triple loop-learning.

Thus, reflecting occurs on various levels of complexity: single-loop, double-loop and triple-loop learning. The various problems in the above described examples, as they might occur in any teacher's workplace, ask for reflecting at all the levels. In order to develop into a starting expert, teachers in training need to go through a process that improves their actions, enriches their way of looking at their practice and further develops their identity. This means that learning objectives need to be set during their education to support the process of loop learning.

To enable teachers in training to practice with a range of loops, Bloom stresses the importance of facilitating higher learning objectives (Bloom, 1979; Kratwohl, 2002). According to Bloom, learning occurs at six levels: remembering, understanding, applying, analyzing, evaluating and creating (Athanassiou \& McNett, 2003). While the first three of these deal mainly with factual knowledge, analyzing, evaluating and creating are considered higher learning objectives.

Because higher learning objectives are more complex by nature, and therefore focused on, for example, evaluations and analysis carried out by the learner (Jideani \& Jideani, 2012), they are particularly suitable to stimulate teachers in training to link theoretical knowledge to a practical situation. These real-world experiences can be linked to the theoretical part of the teacher training by showing video cases during the courses (Geerts, Van der Werff, Hummel, Steenbeek, \& Van Geert, 2015; van Es, Stockero, Sherin, Van Zoest, \& Dyer, 2015).

Video cases are holistic and contextual, which is why they stand close to the real-world workplace of a teacher. This similarity is a first requirement for video cases to serve as an adequate replacement of reflecting on practical real-world experiences. An added advantage of video-cases is that it can be used at any moment during the course. Waiting for practical experience from an internship, and the presence of a mentor or supervisor is a time-consuming and therefore costly affair. By watching video cases, a teacher in training is able to use his theoretical knowledge to reflect on the educational situation that is shown in the video by analyzing and exploring how an experienced teacher deals with those particular circumstances (Blijleven, 2005; Kurz, Llama, \& Savenye, 2008). This way, the teacher in training is challenged to develop an increasingly rich combination of design patterns and educational purposes, or, situated knowledge. Situated also means that the context is essential not just for developing the knowledge, but also for applying it.

\subsection{Goals of This Research}

The current research is explorative in nature and focuses on the development of a teacher in training to a starting expert. The central question of this research is: Does the situated knowledge of a fourth-year teacher in training match that of a starting expert? Based on the theoretical framework outlined above, a teacher in the final year of his training can be expected to have reached the level of a starting expert. A starting expert possesses a wide range of situated knowledge to deal with the most common situations in a classroom. The process that is used to acquire this situated knowledge is fed by reflection on the theoretical knowledge he has studied, combined with his practical experiences, and may or may not be supported by video cases. A starting expert, therefore, is in possession of learning outcomes based on single-, double-, and triple-loop learning (Argyris, 2002). The first expectation of the researchers is that a teacher in training in the final year of his training goes through all three levels of loop learning, and therefore goes through the reflection process in its entirety. The situated knowledge thus obtained by him includes a variety of both educational purposes and design patterns. This situated knowledge is reflected in his analysis of a video case. Secondly, we expect that a substantial number of design patterns and educational purposes can be identified in the teacher in training's analysis of the video case. 


\section{Method}

\subsection{Respondents}

All 33 fourth-year teachers in training at the language department of the NHL Hogeschool were asked to take part in this research in pairs. Working partially in pairs is representative of the approach of the researched training which, in its educational didactics, regularly works in pairs. For instance, most internships are organized in pairs. The respondents received one EC for their participation. They gave permission for the use of their advice in the research. Because of the division in pairs and the uneven number of participants, one respondent was not included the study, as he could not be matched with another respondent. The remaining 32 respondents could each choose which case they wanted to study, from a collection of 26 cases. An initial analysis revealed that all cases, save for one, were suitable for drafting an advice with enough substance for further analysis. Because the research was set up in a way that is focused on detailed reporting, the number of respondents was cut further. Only two cases were picked by multiple dyads, that is, both of them were picked by two dyads. Because of the desired spread over the characteristics of the entire group of respondents outlined below, the respondents that worked with the case of Olga were selected. From the respondents whose data was finally used, none had to repeat a grade year. It concerns three female students and one male, in the ages of 25 to 27 . Because the average student completes the training in 5.5 years, these ages are representative for students in the fourth year of their training. The percentage of male students that enrolls for this training nationwide is around $40 \%$ (CBS, 2016), but compared to the numbers of men and women enrolled at teacher training at the NHL, the gender ratio in the two selected student pairs is representative.

\subsection{Case Study}

In the following research, the term case is used in two meanings. The first meaning refers to the nature of one of the materials being used in this research, that is, a video case, which involves the teacher in training giving an advice to the main character of the video clip representing a real-life situation. However, the second meaning of case concerns our research methodology, because the research is limited to a particular, exemplary case. The exemplary case concerns the reactions of the two student pairs to the video case that have been selected for further study. Such a case indicates a particular situation, example or event. Although case research is often regarded as a means to tell something about a single, specific, situation, this method can also provide general knowledge when the case is exemplary and is meeting a set of specific requirements (Flyvbjerg, 2006). Yin (2009) describes four requirements which must be met for a case to provide scientifically relevant information.

First of all, a case must be representative of the situated knowledge that fourth-year teachers in training have acquired. This requirement is met when the situated knowledge, as described through educational purposes and design patterns, is actually observable in the advice the students give as a reaction to the video. An authentic problem, which the video case focuses on, invites teachers in training to name certain elements of good classroom management. The authentic problem concerns the main character in the video clip having difficulties with carrying out her role of teacher in terms of classroom management. The associated higher order learning objective understands the relationship between the reactions of students and the way the role of teacher is carried out. The teacher in training is aware of this once he recognizes the link between his actions and the students' reaction to those actions. When it comes to personal identity, the central question is whether the teacher is feeling responsible for the order in the classroom.

The second requirement, which requires the case to be complete, is met when the key features necessary to give good advice, consist of a full array of class management skills: a continuous signal, a continuous line in carrying out the lesson; reflection; teacher role; student responsibility; communication and keeping order.

Thirdly, a case, as a means of research, must also offer alternative perspectives on the situation. A video case is ideally suited to give alternative perspectives on the situation, because the viewer is allowed to construct his own reality from the images which have a contextual and holistic nature. To reflect on the situation in the video, the viewer must possess a certain amount of knowledge. An absolute beginner probably lacks the theoretical knowledge to come to an adequate reaction. Provided he does possess this theoretical knowledge, he still misses the situated knowledge to create a link with the practical situation shown in the video. On the other hand, an expert can fully express his expertise. After all, not only does he give advice about the cases shown, he also answers questions about the underlying principle of his advice. By justifying his advice on the basis of underlying principles, an expert explicitly demonstrates how he has come to his advice and what kind of reflection has been used. The video cases that are shown encourage the fourth-year teachers in training to express alternative explanations.

The best way to meet the fourth requirement, the requirement of sufficient evidence, is to observe repeatedly. 
That is why the assignment related to the video case consists of three instruments. The first instrument is aimed at defining the core of the dilemma shown in the case. The second instrument consists of putting forward an advice for the main character in the case. The third instrument is an individual interview with the respondents. Because converging evidence is collected from different sources, the risk of basing the finding on chance alone is reduced. To determine the reliability of the measurement method, some thirty teacher trainers at the Velon Congress of 6 February 2012, with more than five years of experience in the vocational preparation, were presented the case (Velon, 2012). The answers of five pairs of these experts form the framework for the set of criteria for the quality of the answers of the starting experts: number of reflective loops, design patterns and educational purposes. This way, the case allows for discrimination between the answer of a beginner and the answer of an expert.

These instruments are further validated by means of the authentic evaluations of the students at issue. This additional information gives an indication of the fact that the respondents, in terms of both the results of the written test and the results of the internship, are recognised as starting experts.

\subsection{Testing in Pairs}

Since the instruments will be used to describe a knowledge acquisition process, two out of three tests will be done in pairs. It is difficult to study the knowledge acquisition or reflection processes of a single individual (Fisher \& Grannot, 1995). The person being examined will not, for instance, be thinking out loud and will show little of his internal thoughts in his behaviour. In addition, a researcher who forces his research object to think out loud during his activity, will not be able to observe a natural behavioural process. In daily activities, the interaction with other members of the group can be an important mechanism for learning (Anderson \& Soden, 2001). Moreover, it is natural for humans to learn or solve something in collaboration with others (Bahrami et al., 2010). In fact, there is consensus that cooperation between two individuals enables them both to reach higher order learning levels (Kerr \& Tindale, 2004).

The yield of the knowledge acquisition process depends on the type of interaction occurring between the individuals in a pair. There are situations in which a pair is not performing better than the individual, for instance, when communication between the two is not possible, or when there is inequality of contribution, because one of the members displays more confidence, without there being a good reason for it (Kerr \& Tindale, 2004). To reduce potential inequality in the interaction, an individual post-test will be performed.

\subsection{Procedure}

All fourth-year students gave a simulated advice to the virtual main character of a video case of their choice. The case base consists of a variety of authentic recordings which portray a dilemma of a teacher in training. One of the authors of this study also co-authored the video clip library called Didiclass from which these dilemmas were selected. For this research, a video case combined with an assignment composed of three parts, has been used.

The assignment, given to a pair of students, consists of two parts. The first part focuses on describing the essence of the dilemma featured in the video case. The second part consists of writing an advice to the main character in the chosen Didiclass case, suitable for the person, their practice (or practical situation) and the theoretical knowledge related to case. With these questions, respondents could show how many design patterns and educational purposes they were able to recognise in the video, and furthermore which level of loop learning they were using. Their advices were drawn up by the collaborating students during a course of vocational preparation at the NHL. Watching the video and writing the advice took approximately thirty minutes.

Thereafter, a semi structured interview was carried out with each individual student, consisting of the following questions:

1) Why have you chosen this case?

2) Which questions would you like to ask the main character?

3) Which vision of teaching is at the root of your advice?

4) Have you used a theoretical basis? If so, which one?

5) Have you used your own experiences when you put together your advice? If so, which one?

6) What can you learn from this case yourself?

Through this individual interview, possible inequalities in the interaction that arise from a group effect, can be determined and considerably reduced, if the individual answers correspond with the advice they gave as a pair.

Since a thorough analysis of the answers to the two video cases watched by the respondents would exceed the 
scope of the current article, it was decided to focus on the answers to one particular case only. This case was randomly selected, and features a teacher called Nienke. The authentic problem which is central in this case is the novice teacher having difficulty defining her role as a teacher. Key features are a continuous signal, reflection, teacher role, student responsibility, communication and keeping order. The higher order learning objective that may well be reached is that a teacher in training gains insight in the relationship between the reactions of students and the way the role of the teacher is fulfilled.

Based on knowledge of the abovementioned procedure and the corresponding possible answers, the expectations defined in advance can be made more concrete. The first expectation, reflecting on the level of a starting expert, is met if there are at least two detailed specifications per reflection level for the applied case. The second expectation, situated knowledge at the level of a beginning expert, is met when, in the answers of the teachers in training, at least four different design patterns and educational purposes can be identified.

\subsection{Data Analysis Procedure}

To determine the degree of loop learning and the number of educational purposes, the advice given by the student pairs, as well as the individual interviews in response to the video case, have been analysed by a pair of education experts. This analysis can be summarized below, in rating Table 1.

Table 1. Rating table for loop levels, educational purposes and design patterns

\begin{tabular}{|c|c|c|c|}
\hline Note & Loop learning & Educational purposes & Design pattern \\
\hline Advice & & & \\
\hline Reply 1 & & & \\
\hline Reply 2 & & & \\
\hline Reply 3 & & & \\
\hline
\end{tabular}

The first part of the table is used to determine per given answer or advice if there is single-loop, double-loop of triple-loop learning. To be able to rate this in a uniform way, table 2 has been used. In this table, loops are defined in the column 'explanation'. The column 'signal words' shows examples of concepts that indicate that reflection takes place on, for instance, actions (single-loop). The final column shows, for every loop, examples of the answers from the advices of the respondents. "I will stand by the door", contains the signal words 'I will stand' and is thus a reflection on an action, i.e. single-loop learning. Because triple-loop learning involves all subjacent learning loops, the scoring also involves a loop procedure. If the signal words for single-loop learning are found, a possible extension to double- or even triple loop needs to be explored. Therefore, a quote on triple-loop learning is frequently much longer than a quote on single-loop learning.

Table 2. Rating procedure single-, double-, and triple-loop learning

\begin{tabular}{llll}
\hline $\begin{array}{c}\text { Loops of } \\
\text { Argyris }\end{array}$ & \multicolumn{1}{c}{ Explanation } & \multicolumn{1}{c}{ Signal words } & \multicolumn{1}{c}{ Answer given } \\
\hline Single-loop & $\begin{array}{l}\text { Improving the existing action procedure } \\
\text { that is applied to reach the underlying } \\
\text { objective. }\end{array}$ & $\begin{array}{l}\text { I'm doing, I'm going to, I will, I'm } \\
\text { making, I'm making sure that, I'm } \\
\text { acting }\end{array}$ & $\begin{array}{l}\text { For example: I'm going to stand by the } \\
\text { door, which enables me to have a better } \\
\text { overview. }\end{array}$ \\
\hline Double-loop & $\begin{array}{l}\text { New insights that can lead to changes in } \\
\text { behaviour. }\end{array}$ & $\begin{array}{l}\text { I think, I know, I understand, I have } \\
\text { discovered }\end{array}$ & $\begin{array}{l}\text { For Example: I have discovered that, } \\
\text { when I'm standing by the door, I have a } \\
\text { better overview }\end{array}$ \\
\hline \multirow{2}{*}{ Triple-loop } & $\begin{array}{l}\text { Perception of personal principles and } \\
\text { higher order goals that are considered } \\
\text { important. }\end{array}$ & I want to, I am, I would like to be & $\begin{array}{l}\text { For example: I value contact with people, } \\
\text { that's why I want to greet people by the } \\
\text { door. }\end{array}$ \\
\hline
\end{tabular}

Subsequently, it was determined under which educational purpose or design pattern a particular answer falls. The fact that educational purposes occur in the answers becomes clear from the occurrence of guiding principles, statements of educational purposes, 'action link' between cause and effect, practical generalisations that the respondent uses, relationship with educational theories, negative value judgements about certain actions, justified changes and positive value judgements (Copeland \& D'Emidio-Caston, 1998). Table 3 below shows two examples of the scoring of educational purposes. The entire table is included in appendix A. 
Table 3. Rating procedure educational purposes

\begin{tabular}{|c|c|c|}
\hline $\begin{array}{l}\text { Indicators } \\
\text { Educational } \\
\text { purposes }\end{array}$ & Explanation & Example \\
\hline $\begin{array}{l}\text { Negative value } \\
\text { judgement }\end{array}$ & $\begin{array}{l}\text { Extracts that give negative value judgements, } \\
\text { about an event in the video (including } \\
\text { justifications). }\end{array}$ & $\begin{array}{l}\text { "She doesn't know her weaknesses" and "because of that, she } \\
\text { falls into traps" (about the teacher's performance in the video } \\
\text { case). }\end{array}$ \\
\hline $\begin{array}{l}\text { Positive value } \\
\text { judgement }\end{array}$ & $\begin{array}{l}\text { Extracts that give positive value judgements about } \\
\text { an event in the video (including justifications). }\end{array}$ & "She is motivated to bring the lesson to a good end." \\
\hline
\end{tabular}

Finally, to determine the design pattern, we checked which design pattern is leading in the answer provided. For the categorisation into design patterns, field coding from a previous study (of second year students), has been used (Geerts, Van der Werff, Hummel, Steenbeek, \& Van Geert, 2015). The following main categories of design patterns have been used: pedagogical action, dealing with human characteristics, interaction with the environment, instruction, learning process, dealing with disorder, self-management, coaching, learning in practice and reflection. In general, the answer can be easily categorised. If, for example, the answer involves the learning process, it should be categorised in the design pattern learning process, and not in the design pattern instruction. Sometimes, however, categorisation is more difficult, for example with the following two answers which both involve the teacher planning to stand at the door of the classroom. When the teacher notes that it is better to stand at the door to welcome the students, that remark is categorised in the design pattern 'pedagogical action'. On the other hand, if the answer describes that the teacher is standing at the door to prevent disorder, it is categorised in the design pattern 'dealing with disorder'. These answers demonstrate that, using the assessor's expertise, a sound categorisation could be ensured. Additionally, two further examples of the scoring of design patterns have been provided in table 4 .

Table 4. Scoring procedure design patterns

\begin{tabular}{lll}
\hline Design pattern & Explanation & Example \\
\hline $\begin{array}{l}\text { Providing } \\
\text { instruction }\end{array}$ & $\begin{array}{l}\text { Extracts focused on the design pattern giving } \\
\text { instruction, emphasizing the presentation. }\end{array}$ & "She references the things they (the students) did last week." \\
\hline \multirow{2}{*}{$\begin{array}{l}\text { Guiding the } \\
\text { learning process }\end{array}$} & $\begin{array}{l}\text { Extracts focused on the design pattern guiding "She wants her students to learn something, I think she covered } \\
\text { learn. }\end{array}$ & $\begin{array}{l}\text { German } \\
\text { learne words, vocabulary, and wants them to know them in }\end{array}$ \\
\hline
\end{tabular}

The entire abovementioned procedure is repeated by another pair of educational experts who were not part of the research group. Subsequently, an interrater reliability analysis has been conducted, to determine the consistency between assessors, by means of calculating Cohen's Kappa (Landis \& Koch, 1977). For the inter-assessors-reliability regarding loop learning, a Kappa of $0.94 \quad(p<0.001)$ was obtained. The inter-assessors-reliability regarding design patterns, yields a Kappa of $0.93(\mathrm{p}<0.001)$. This means that there is a high inter-assessors-reliability. It is likely that this results from working in pairs. Because they regularly consult each other during the assessment process, the assessors in an assessor pair converge towards similar, well-considered assessments. To support the qualitative data, which analysed the given answers on the levels of reflection, educational purposes and design patterns, the results section also contains the qualitative data: the answers as they have been given by the respondents.

\section{Results}

In order to answer the question as to what extent the fourth-year teachers in training behave as beginning experts, i.e. reflect on all three loops of Argyris and demonstrated various educational purposes and design patterns, firstly a selection of the answers of Respondent D., who was randomly selected, is provided in table 5. The complete overview can be found in appendix B. 
Table 5. Answers Respondent D. to case Bonte

\begin{tabular}{|c|c|c|c|}
\hline Answers & Reflection loop learning & Educational Purposes & Design Patterns \\
\hline 9 & Single & Theory link & Pedagogical action \\
\hline 10 & Double & Guiding principle & Reflection \\
\hline 11 & Double & Action link & Instruction \\
\hline 12 & Triple & Justified change & Dealing with disorder \\
\hline
\end{tabular}

What stands out in the first column of Table 5, which contains four answers of Respondent D., is the fact that a spread over single-loop, double-loop, and triple-loop learning concerning the provided individual answers can be discerned. Respondent D., therefore lives up to the first expectation: a minimum of two examples of loop-learning at all three levels. The following columns show which design pattern the loop represents, and what the underlying educational purpose is.

Secondly Table 6 summarises, per teacher in training, if the loops in the reflection process are being supported by a minimum of two different answers per loop like the first expectation specifies. We can see that the unique educational purposes and the unique design patterns usually total four or more. This observation largely confirms the second expectation. If we look at the difference between the respondents in table 6 , it is noteworthy that Respondents D. and T. evidently show more loop-learning than Respondent P. and M. Besides a larger number of loops, D. and T. also seem to possess a greater diversity of unique design patterns.

Table 6. Overview of scores of the respondents

\begin{tabular}{|c|c|c|c|c|c|c|c|c|}
\hline \multirow{2}{*}{ Respondent } & \multicolumn{3}{|c|}{ Loop learning } & \multirow{2}{*}{$\begin{array}{l}\text { Loop learning } \\
\text { (total number) }\end{array}$} & \multirow{2}{*}{$\begin{array}{c}\text { Unique educational } \\
\text { purposes }\end{array}$} & \multirow{2}{*}{$\begin{array}{c}\text { Unique design } \\
\text { patterns }\end{array}$} & \multirow{2}{*}{$\begin{array}{l}\text { Evaluation } \\
\text { internship }\end{array}$} & \multirow{2}{*}{$\begin{array}{c}\text { Evaluation } \\
\text { test }\end{array}$} \\
\hline & Single & Double & Triple & & & & & \\
\hline $\mathrm{D}$ & 9 & 9 & 4 & 22 & 7 & 9 & $\mathrm{~V}$ & $\mathrm{G}$ \\
\hline $\mathrm{T}$ & 6 & 8 & 2 & 16 & 4 & 6 & $\mathrm{~V}$ & $\mathrm{G}$ \\
\hline $\mathrm{P}$ & 6 & 3 & 3 & 12 & 4 & 2 & $\mathrm{~V}$ & G \\
\hline M & 6 & 3 & 4 & 13 & 5 & 4 & V & G \\
\hline
\end{tabular}

The maximum number of unique educational purposes has been limited to eight, because there are only eight educational purposes. Respondent D. reported 22 educational purposes, seven of which were unique. This is a typical type-token ratio, namely seven types over 22 tokens. The educational purposes 'guiding principle' and 'justified change' were mentioned most frequently, as shown by the bar chart in Figure 1.

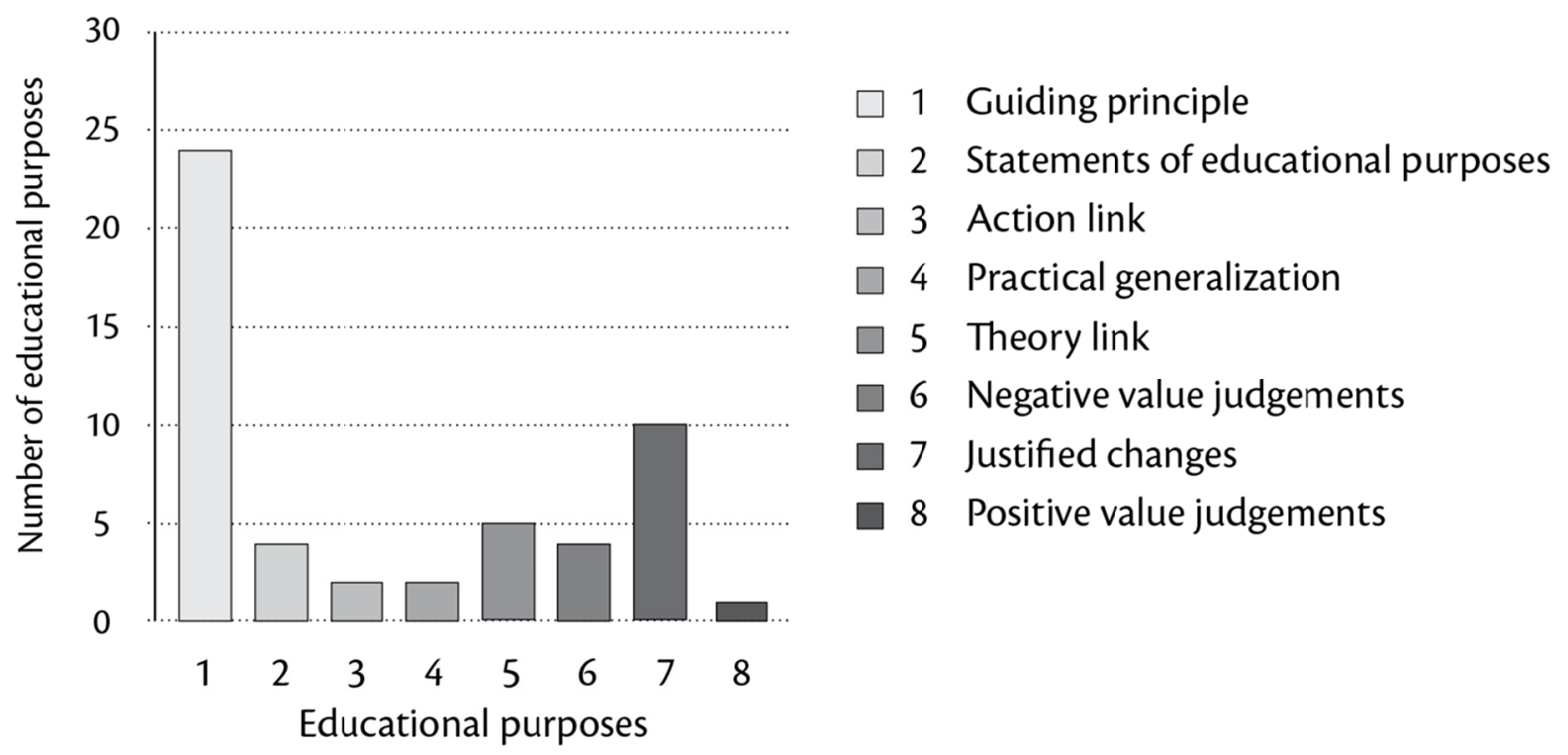

Figure 1. Number of educational purposes 
Regarding the reported design patterns, the answers of all respondents together prove that 'reflection' and 'dealing with disorder' are the predominant design patterns, as figure 2 shows. Despite the emphasis on these two design patterns, this bar chart demonstrates a spread amongst all ten scoreable design patterns.

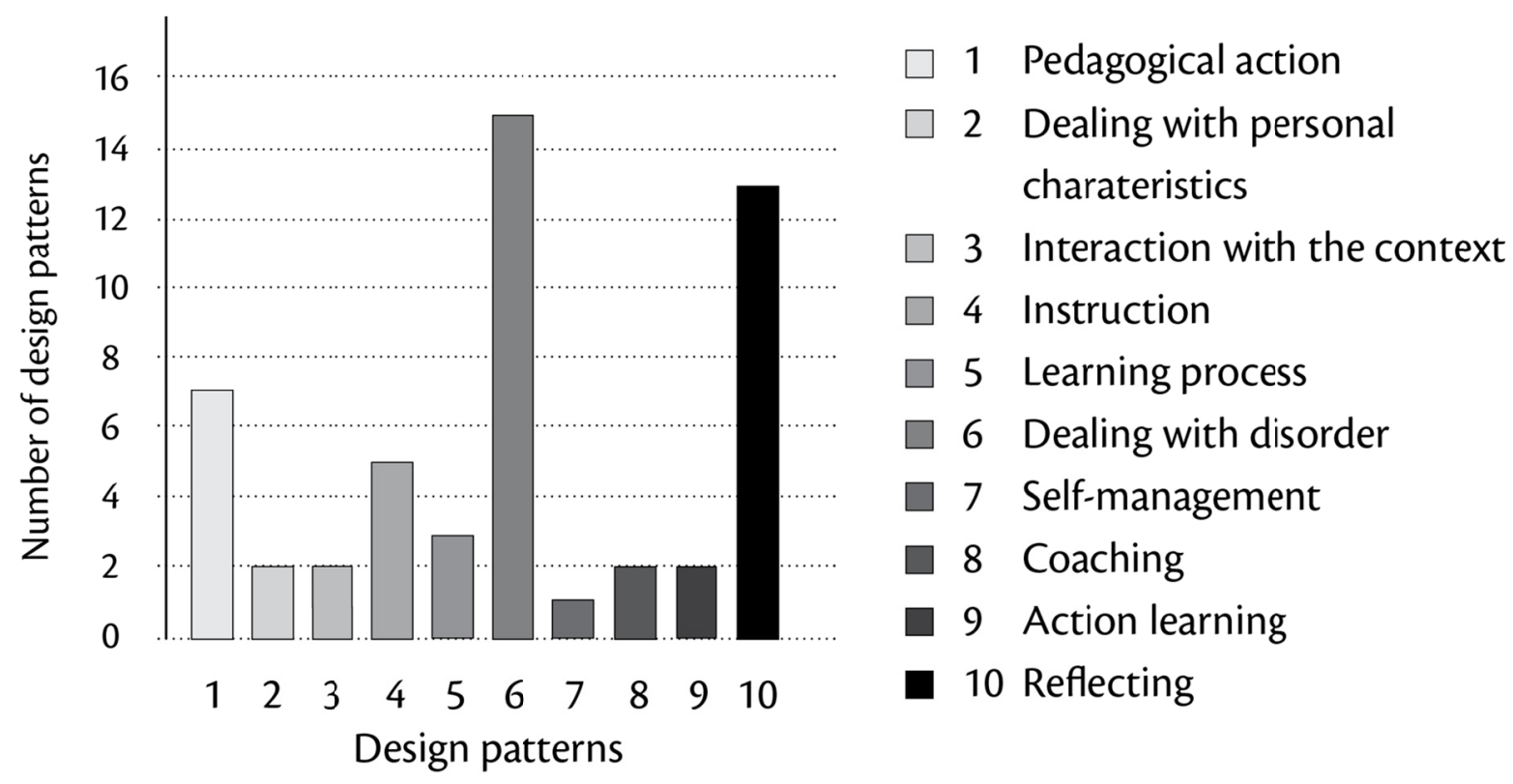

Figure 2. Numbers of design patterns

We have already concluded that all respondents meet the first expectation, namely a minimum of two instances of loop-learning on all three levels. To illustrate how the respondents express these orders of learning, a few examples follow below.

The first quote is derived from the advice that was given to the main character of the case.

Quote 1: 'We have seen that you issue warnings, but that you don't connect consequences to these warnings. Take action sooner.'

This quote is rated as being a reflection on single-loop learning, because the clues are presented to the main character in the video case about the way she must employ an action procedure in order to achieve the underlying goal. The educational purpose is rated as 'justified change', because a motivation is given for the advice. This motivation is linked to what has been seen in the video. In terms of design pattern, it concerns 'dealing with disorder'.

The second quote came as a reply to a question regarding what the student wants to employ in his own teaching practice.

Quote 2: 'I often sit on the table, which basically is not very different from sitting behind your desk. I saw Nienke sitting behind her desk often and I, myself sit still a lot, so I started walking through class more often, making more use of space. Doing so has been a conscious decision. Sitting on tables is basically the same as behind a desk, because you're static in one place, except that you are a little more visible. I notice that I speak to someone more quickly: how are things here? When I'm in a different spot, I have a view on some other things.'

This quote indicates that the student has received a new insight, which can be characterised as reflection on double-loop learning. The underlying educational purpose is identified as a 'guiding principle', because the description defines what a teacher is supposed to do in a comparable situation. The accompanying design pattern is 'pedagogical action'.

The third quote individually answers the question which vision on teaching is at the root of the advice given to the main character of the case.

Quote 3: 'Currently I work at a vmbo school, at the lowest levels, and I can picture myself in the role that I 
stepped into earlier, as a coach. I'm the one who guides the learning process, I'm there for the questions, for the information. I want to work with a class to reach a situation where things can be accomplished. But that is not primarily what it's about. It's also about the development of the child and that is not solely oriented at teaching English, and this is especially true for the vmbo. There are a lot of other things involved, which are often slightly more important than that: how do I learn for a test? And what about this whole list of words? How do I make sure that I know all of them by heart? In that sense, it is different from teaching at havo/vwo (Note 1). It's all a bit more didactical I would say. And it's not that there's too little focus on my subject, it quite suits me. But sure, I'm less focused on my subject than my fellow students who are at havo/vwo. They can put more focus on their subject. With me, it's about learning skills, processing strategies, but also social skills, how do we treat each other, how come we don't live by the rules and where does it go wrong? And that is often just a bit more important than the actual curriculum.

The quote above encompasses reflection that is expressed through triple-loop learning, because the student demonstrates that she is obtaining more perspective on her own principles and higher goals: the things she thinks are important. The underlying educational purpose is 'guiding principle', because she outlines what a coaching teacher is supposed to do. Substantively, it encompasses the design pattern 'coaching'.

\section{Conclusion and Discussion}

In this research, two expectations have been formulated regarding the similarities between the behaviour of a fourth-year teacher in training and that of a beginning expert. The first expectation is that fourth-year teachers in training complete their reflection process, and thus go through loop-learning on all three levels of Argyris. The second expectation is that they will be able to recognise a variety of educational purposes and design patterns in a practical situation, as shown on video.

The given answers indicate that with the four students, reflection on all three loops can be identified. The reflection on these three loops occurs at least two times in their answers, either in the individual answer, or in the answers they gave as a pair. With that, all respondents meet the first expectation, that is, they demonstrate comprehension of reflection. This indicates that in four years' time, they go through a learning process that concerns the improvement of pre-existing action, new insights and personal identity. The second expectation, four unique educational purposes, and design patterns, is met by three out of four respondents. Respondent $P$. mentions only two unique design patterns in total. In summary, based on the case test, three out of four teachers in training can be characterised as beginning experts, because they met both expectations.

The conclusion demonstrates that the reflection and situated knowledge of fourth-year students largely corresponds to what may be expected of a starting expert. The spread over the different loops of Argyris (2002) can be explained with the underlying learning process of the teacher in training, concerning improvement of pre-existing action, new insights and personal identity. The fact that this situated knowledge also consists of a diversity of educational purposes and design patterns are supported by the given answers. The answers given by the experts turned out to contain the maximum number of both unique educational purposes and unique design patterns. This can be explained using the increase in situated knowledge in a fully developed expert compared to a starting expert. Finally, it should be noted that this development is not linear in character (Fisher, 1980).

Looking back, the fact that 'dealing with disorder' is the most frequently mentioned design pattern is not surprising, because this design pattern is conditional for proper teaching. The fact that this design pattern scores this high, however, may be worrying, as it is an indication that the teacher in training is preoccupied with dealing with disorder, which might have an impeding effect on acquiring other design patterns. After all, in the final year of the education it may be expected that the teacher in training already masters this pattern sufficiently. The fact that 'reflection' is the other most commonly named design pattern, could be part of a normal development of a teacher in training. However, it cannot be ruled out that the training is excessively focused on this aspect. If the curriculum at the teacher training mainly consists of 'dealing with disorder', then it is, of course, logical that the teachers in training apply this design pattern frequently on the video cases that were used.

The fact that 'guiding principles' is by far the most often named educational purpose, has possibly to do with limitations of the research. With a guiding principle, the respondent indicates: 'that's the way it's supposed to be'. The strong emphasis on process goals likely implies that other motivations will be far less frequently given. On the one hand, this could also be caused by a limited diversity of educational purposes. On the other hand, the cause could be found in the fact that the study is insufficiently able to map the available diversity of educational purposes.

Finally, regarding the possible limitations of the research, the individual contribution of each respondent could be questioned because part of the answers emerged from working together in pairs. The results of the 
individually conducted interview, however, suggest that the responses are in line with the results from the pairs.

From the above it follows that further research on the preoccupation of teachers in training with the design pattern 'dealing with disorder' is necessary, as this preoccupation might interfere with obtaining other design patterns. If the high percentage of reported guiding principles is taken into consideration, we cannot exclude the chance that this is the result of a limitation of the current research. New research might rule out that the choice of this particular video case was the reason other principles were less frequently mentioned. The reactions of the experienced teacher trainers indicate that there is an equal distribution of educational purposes.

Based on the results of this research, the advice to teacher trainers is to find a place in their curriculum for situated knowledge. The curriculum should challenge the teacher to link theoretical knowledge with their own teacher practice. When combined with higher learning goals, authentic video clips are appropriate means for stimulating reflection on their experiences teaching.

It should be noted that the teacher trainer is focused on helping the teachers in training to consistently reflect on all three different loops of Argyris. Full reflection is, after all, spread over all of them. This way, a learning process emerges that involves improving existing action patterns, new insights and personal identity. The situated knowledge that is built in this way consists of a diversity of educational purposes and design patterns. This means that a teacher trainer needs to include work forms in his didactical approach that contribute to the situated knowledge in his students. On top of that, his testing needs to be in line with the learning objectives of the courses he teaches. Teacher in training D. expresses this idea in her case test: "The case test made me think: 'Let me just make a video of this class, just to see how things are.' It's nice to start recognizing the way you behave in front of the class. In the beginning, it's very much a directed affair and very thought through. Near the end of the year, it all begins to run smoothly and you find yourself thinking: 'I am myself in front of the class... and it works!"”

This quote illustrates the most important conclusion of this research: the reflection and situated knowledge of the respondents, fourth-year teachers in training, are equivalent to what can be expected of a starting expert. A shortcoming of this research is the focus on the design pattern 'dealing with disorder'. Future research needs to systematically pay attention to mapping the distribution of educational purposes and design patterns. In this article, after all, it has been shown that these concepts are a usable operationalization of the situated knowledge, which is important for an adequate response to the complex and diffuse situations in educational practice. Finally, from the results as a whole, and especially this quote, we can gather that the use of video, in combination with higher learning goals, is an important ingredient of effective teacher education.

\section{References}

Abrahamson, D., \& Sánchez-García, R. (2016). Learning is moving in new ways: The ecological dynamics of mathematics education. Journal of the Learning Sciences, 25(2), 203-239. https://doi.org/10.1080/10508406.2016.1143370

Alexander, C., Ishikawa, S., Silverstein, M., Jacobson, M., Fiksdahl-King, I., \& Angel, S. (1977). A Pattern Language- towns, buildings, construction. New York: University Press.

Anderson, T., \& Soden, R. (2001). Peer Interaction and the Learning of Critical Thinking Skills. Psychology Learning and Teaching, 1, 37-40. https://doi.org/10.2304/plat.2001.1.1.37

Argyris, C. (2002). Double-loop learning, teaching, and research. Academy of Management Learning and Education, I(2), 206-218. https://doi.org/10.5465/AMLE.2002.8509400

Athanassiou, N., McNett, J.M., \& Harvey, C. (2003) Critical thinking in the management classroom: Bloom's taxonomy as a leaning tool. Journal of Management Education, 27, 533-555 https://doi.org/10.1177/1052562903252515

Bahrami, B., Olsen, K., Latham, P., Roepstorff, A., Rees, G., \& Frith, C. (2010). Optimally Interacting Minds. Science, 329(5995), 1081-1085. https://doi.org/10.1126/science.1185718

Blijleven, P. J. (2005). Multimedia-cases: Naar een Brug Tussen Theorie en Praktijk (Doctoral dissertation), Universiteit Twente, Enschede. Retrieved from http://doc.utwente.nl/50430/1/thesis_Blijleven.pdf

Bloom, B. S. (1979). Taxonomy of Educational Objectives: The Classification of Educational Goals. In Handbook I: Cognitive domain. London: Longman.

$\begin{array}{ccccrr}\text { Centraal Bureau voor } & \text { de } & \text { Statistiek. (2016). Hoger onderwijs; } & \text { ingeschrevenen, } & \text { studierichting, } \\ \text { herkomstgroepering. } & \text { Retrieved } & 09 & 13, & \text { fol6, } & \text { from }\end{array}$ http://statline.cbs.nl/Statweb/publication/?VW=T\&DM=SLNL\&PA=71037NED\&D1=0\&D2=a\&D3=1\&D4 
$=0-2 \& D 5=0-2,5,1 \& D 6=0 \& D 7=16-20 \& H D=170712-1446 \& H D R=T, G 2, \mathrm{G} 5, \mathrm{G} 6 \& \mathrm{STB}=\mathrm{G} 1, \mathrm{G} 3, \mathrm{G} 4$

Ching, C. P. (2014). Linking Theory to Practice: A Case-based Approach in Teacher Education. Social and Behavioral Sciences, 280-288. https://doi.org/10.1016/j.sbspro.2014.01.1425

Copeland, W. D., \& D'Emidio-Caston, M. (1998). Indicators of development of practical theory in pre-service teacher education students. Teaching and Teacher Education, 14(5), 513-534. https://doi.org/10.1016/S0742-051X(98)00003-1

Copeland, W., Birmingham, C., DeMeulle, L., D'Emidio-Caston, M., \& Natal, D. (1994). Making Meaning in Classrooms: An Investigation of Cognitive Processes in Aspiring Teachers, Experienced Teachers, and Their Peers. American Educational Research Journal, 31(1), 166-196. https://doi.org/10.3102/00028312031001166

Dean, C., Lauer, P., \& Urquhart, V. (2005). Outstanding Teacher Education Programs: What Do They Have That the Others Don't? The Phi Delta Kappan, 87(4), 284-289. https://doi.org/10.1177/003172170508700406

Dubinsky, E. (1991). Reflective abstraction in advanced mathematical thinking. In D. Tall (Ed.), Advanced Mathematical Thinking (pp. 95-123). Dordrecht, The Netherlands: Kluwers

Ericsson, K. A. (2008). Deliberate Practice and Acquisition of Expert Performance: A General Overview. Academic Emergency Medicine: Official Journal of the Society for Academic Emergency Medicine, 15(11), 988-994. https://doi.org/10.1111/j.1553-2712.2008.00227.x

Fischer, K. W. (1980). A Theory of Cognitive Development: The Control and Construction of Hierarchies of Skills. Psychological Review, 87(6), 477-531. https://doi.org/10.1037/0033-295X.87.6.477

Fischer, K., \& Granott, N. (1995). Beyond One-Dimensional Change: Parallel, Concurrent, Socially Distributed Processes in Learning and Development. Human Development, 38, 302-314. https://doi.org/10.1159/000278336

Flyvbjerg, B. (2006). Five Misunderstandings About Case-Study Research. Qualitative Inquiry, 12(2), 219-245. https://doi.org/10.1177/1077800405284363

Geerts, W., Van der Werff, A., Hummel, H. G., Steenbeek, H. W., \& Van Geert, P. L. (2015). Assessing situated knowledge in secondary teacher training by using video cases. EAPRIL 2015. Luxembourg City.

Hattie, J. (2003). Teachers Make a Difference: What is the research evidence? Australian Council for Educational Research.

Jideani, V., \& Jideani, I. (2012). Alignment of Assessment Objectiveswith Instructional Objectives Using Revised Bloom's Taxonomy-The Case for Food Science and Technology Education. Journal of Food Science Education, 34-42. https://doi.org/10.1111/j.1541-4329.2012.00141.x

Kerr, N., \& Tindale, R. (2004, 2). Group Performance and Decision Making. Annual Review of Psychology, 55, pp. 623-655. https://doi.org/10.1146/annurev.psych.55.090902.142009

Kitchener, P., \& King, K. (2004). Reflective Judgment: Theory and Research on the Development of Epistemic Assumptions Through Adulthood. Educational Psychologist, 39(1), 5-18. https://doi.org/10.1207/s15326985ep3901_2

Koriat, A. (2012). When Are Two Heads Better than One and Why? Science, 336(6079), 360-362. https://doi.org/10.1126/science.1216549

Krathwohl, D. R. (2002). A revision of bloom's taxonomy: An overview. Theory into practice, 41, 212-218. https://doi.org/10.1207/s15430421tip4104_2

Kurz, T. L., Llama, G., \& Savenye, W. (2008). Issues and challenges of creating video cases to be used with preservice teachers. TechTrends, 49(4), 67-73. https://doi.org/10.1007/BF02824113

Landis, J. R., \& Koch, G. (1977). The measurement of observer agreement for categorical data. Biometrics, 33(1), 159-174. https://doi.org/10.2307/2529310

Markauskaite, L., \& Goodyear, P. (2014). Tapping into the mental resources of teachers' workingknowledge: Insights into the generative power of intuitive pedagogy. Learning, Culture and Social Interaction, 3, 237-251. https://doi.org/10.1016/j.lcsi.2014.01.001

Miller, K. F. (2011). Situation awareness in teaching: What educators can learn from video-based research in other fields. In Mathematics teacher noticing: Seeing through teachers'eyes (pp. 51-56). 
Piaget, J. (1972). Genetic epistemology. New York: Columbia University Press.

Roth, W., \& Jornet, A. (2013). Situated Cognition. Wiley Interdisciplinary Reviews: Cognitive Science, 4(5), 463-478. https://doi.org/10.1002/wcs.1242

Van der Grift, W. J. (2010). Ontwikkeling in de beroepsvaardigheden van leraren. Groningen: Rijksuniversiteit Groningen.

Van Es, E. A., Stockero, S. L., Sherin, M. G., Van Zoest, L. R., \& Dyer, E. (2015). Making the Most zof Teacher Self-Captured Video. Mathematics Teacher Educator, 4(1).

Van Geert, P. L. C. and Fischer, K. W. (2009). Dynamic systems and the quest for individual-based models of change and development. In J.P. Spencer, M. S. C. Thomas, \& J. McClelland (Editors), Toward a New Grand Theory of Development? Connectionism and Dynamic Systems Theory Reconsidered. Oxford: Oxford University Press. https://doi.org/10.1093/acprof:oso/9780195300598.003.0016

Velon. (2012). Congres voor lerarenopleiders 2012. Vereniging Lerarenopleiders Nederland. Retrieved from $\mathrm{http}: / /$ www.lerarenopleider.nl/velon/congres-voor-lerarenopleiders-2012/

Yin, R. K. (2009). Case Study Research: Design and Methods. Thousand Oaks: Sage Publications.

\section{Notes}

Note 1 . There are three types of secondary education in the Netherlands, each one with its own level and duration:

- Vmbo (Pre-vocational education), which lasts four years;

- Havo (Higher general secondary education), which lasts five years;

- Vwo (Preparatory academic education), which lasts six years.

\section{Appendix A}

Table of indicators from the Copeland and D'Emidio-Caston article (1998)

\begin{tabular}{|c|c|c|}
\hline $\begin{array}{l}\text { Indicators of the } \\
\text { educational } \\
\text { purposes }\end{array}$ & Explanation & Example \\
\hline $\begin{array}{l}\text { Negative } \quad \text { value } \\
\text { judgement }\end{array}$ & $\begin{array}{l}\text { Extracts that express about something that } \\
\text { happened in the video (including } \\
\text { justifications) }\end{array}$ & $\begin{array}{l}\text { "I also think it's wrong, the way she addresses } \\
\text { her pupils" }\end{array}$ \\
\hline Theory links & $\begin{array}{l}\text { Two or more extracts, one containing a } \\
\text { practical generalization and one containing a } \\
\text { guiding principle, which are linked because } \\
\text { of the way it is expressed by the respondent. }\end{array}$ & $\begin{array}{l}\text { "Classroom management: how one behaves in } \\
\text { front of the class, how order is maintained, all of } \\
\text { it is apparent in the video" }\end{array}$ \\
\hline Guiding principles & $\begin{array}{l}\text { Statements on how things are supposed to be. } \\
\text { These statements suggest that the respondent } \\
\text { believes these things are 'correct' and should } \\
\text { be used by all teachers or students. }\end{array}$ & $\begin{array}{l}\text { "I think every teacher should-well I can see her } \\
\text { starting the lesson, and tries to do so in a } \\
\text { positive way, but it doesn't work." }\end{array}$ \\
\hline $\begin{array}{l}\text { Learning objectives } \\
\text { for the pupils }\end{array}$ & $\begin{array}{l}\text { Extracts that descirbe educational objectives } \\
\text { for the pupils, which the teachers work } \\
\text { towards }\end{array}$ & $\begin{array}{l}\text { "She wants her students to learn something, I } \\
\text { think she covered some words, vocabulary, and } \\
\text { wants them to know them in German" }\end{array}$ \\
\hline $\begin{array}{l}\text { Practical } \\
\text { generalizations }\end{array}$ & $\begin{array}{l}\text { Extracts that expresss the possibility of a } \\
\text { general condition that, according to the } \\
\text { respondent, can be found in multiple classes }\end{array}$ & $\begin{array}{l}\text { "And the pupils don't seem to be listening to her, } \\
\text { which gives off a little bit of an impression of } \\
\text { what she is like." }\end{array}$ \\
\hline $\begin{array}{l}\text { Action links between } \\
\text { cause and effect }\end{array}$ & $\begin{array}{l}\text { Extracts that express a causal relation } \\
\text { between a particular action of the teacher in } \\
\text { the video, and the observed pupil behavior }\end{array}$ & $\begin{array}{l}\text { "Olga addresses her pupils in a negative way, } \\
\text { which causes her pupils to react negatively. And } \\
\text { because they don't want to cooperate, this } \\
\text { influences Olga, because she wants them to }\end{array}$ \\
\hline
\end{tabular}




\begin{tabular}{|l|l|l|}
\hline & & $\begin{array}{l}\text { cooperate, and tries her best to get them to, but } \\
\text { not in the right way. It doesn't appeal to the } \\
\text { students." }\end{array}$ \\
\hline Justified change & $\begin{array}{l}\text { Changes are suggestions the respondent } \\
\text { makes for adjusting the lesson that is seen in } \\
\text { the video. They are justified with reasons for } \\
\text { the changes. }\end{array}$ & $\begin{array}{l}\text { She started her lesson by talking about the } \\
\text { unrest in the classroom. I would make sure to } \\
\text { save something like that for the end of the class. } \\
\text { Using it to start the lesson off with, means a bad } \\
\text { start, which will only stress you out." }\end{array}$ \\
\hline $\begin{array}{l}\text { Positive } \\
\text { judgements }\end{array}$ & $\begin{array}{l}\text { Extracts which express value judgements } \\
\text { about something that happened in the video } \\
\text { (including justifications) }\end{array}$ & $\begin{array}{l}\text { "She is motivated to bring the lesson to a good } \\
\text { end. }\end{array}$ \\
\hline
\end{tabular}

\section{Appendix B}

\section{Complete scoring table}

\begin{tabular}{|c|c|c|c|c|c|}
\hline Answer & \multicolumn{3}{|c|}{ Loop learning } & Educational purpose & Design pattern \\
\hline \multicolumn{6}{|c|}{ Advice (in pairs, D \& T) } \\
\hline 1 & Single & & & Negative value judgements & Reflecting \\
\hline 2 & Single & & & Justified change & Pedagogical action \\
\hline 3 & Single & & & Justified change & Dealing with disorder \\
\hline 4 & Single & & & Justified change & Instruction \\
\hline 5 & Single & & & Guiding principle & Reflecting \\
\hline \multicolumn{6}{|c|}{ Advice (in pairs $P$ \& M) } \\
\hline 1 & Single & & & Guiding principle & Dealing with disorder \\
\hline 2 & Single & & & Guiding principle & Dealing with disorder \\
\hline 3 & Single & & & Statement of educational purposes & Dealing with disorder \\
\hline 4 & Single & & & Guiding principle & Dealing with disorder \\
\hline 5 & Single & & & Statement of educational purposes & Dealing with disorder \\
\hline 6 & Single & & & Guiding principle & Dealing with disorder \\
\hline \multicolumn{6}{|l|}{$\mathrm{D}$} \\
\hline 1 & & Double & & Justified change & Reflecting \\
\hline 2 & Single & & & Positive value judgements & $\begin{array}{l}\text { Dealing with personal } \\
\text { characteristics }\end{array}$ \\
\hline 3 & Single & & & Negative value judgement & $\begin{array}{l}\text { Dealing with personal } \\
\text { characteristics }\end{array}$ \\
\hline 4 & Single & & & Guiding principle & Reflecting \\
\hline 5 & & Double & & Guiding principle & Action learning \\
\hline 6 & & & Triple & Guiding principle & Action learning \\
\hline 7 & & & Triple & Guiding principle & Coaching \\
\hline 8 & & & Triple & Theory link & Coaching \\
\hline 9 & Single & & & Theory link & Pedagogical action \\
\hline 10 & & Double & & Guiding principle & Reflecting \\
\hline 11 & & Double & & Action link & Instruction \\
\hline 12 & & & Triple & Justified change & Dealing with disorder \\
\hline 13 & & Double & & Justified change & Self-management \\
\hline 14 & & Double & & Statement of educational purposes & Learning process \\
\hline 15 & & Double & & Guiding principle & Reflecting \\
\hline 16 & & Double & & Guiding principle & Reflecting \\
\hline 17 & & Double & & Guiding principle & Pedagogical action \\
\hline \multicolumn{6}{|l|}{$\mathrm{T}$} \\
\hline 1 & & Double & & Negative value judgement & Reflecting \\
\hline 2 & & Double & & Negative value judgement & Interaction with the context \\
\hline 3 & & Double & & Theory link & Pedagogical action \\
\hline
\end{tabular}




\begin{tabular}{|c|c|c|c|c|c|}
\hline 4 & & Double & & Guiding principle & Learning process \\
\hline 5 & Single & & & Guiding principle & Instruction \\
\hline 6 & & Double & & Guiding principle & Instruction \\
\hline 7 & & Double & & Guiding principle & Instruction \\
\hline 8 & & & Triple & Guiding principle & Reflecting \\
\hline 9 & & Double & & Justified change & Interaction with the context \\
\hline 10 & & & Triple & Theory link & Dealing with disorder \\
\hline 11 & & Double & & Justified change & Reflecting \\
\hline \multicolumn{6}{|l|}{$\mathrm{P}$} \\
\hline 1 & & Double & & Guiding principle & Dealing with disorder \\
\hline 2 & & & Triple & Guiding principle & Dealing with disorder \\
\hline 3 & & Double & & Statement of educational purposes & Pedagogical action \\
\hline 4 & & & Triple & Theory link & Dealing with disorder \\
\hline 5 & & & Triple & Guiding principle & Dealing with disorder \\
\hline 6 & & Double & & Justified change & Pedagogical action \\
\hline \multicolumn{6}{|l|}{ M } \\
\hline 1 & & Double & & Action link & Reflecting \\
\hline 2 & & & Triple & Guiding principle & Learning process \\
\hline 3 & & & Triple & Justified change & Pedagogical action \\
\hline 4 & & & Triple & Guiding principle & Dealing with disorder \\
\hline 5 & & Double & & Practical generalization & Reflecting \\
\hline 6 & & & Triple & Guiding principle & Reflecting \\
\hline 7 & & Double & & Practical generalization & Dealing with disorder \\
\hline
\end{tabular}

\section{Copyrights}

Copyright for this article is retained by the author(s), with first publication rights granted to the journal.

This is an open-access article distributed under the terms and conditions of the Creative Commons Attribution license (http://creativecommons.org/licenses/by/4.0/). 